DOI: https://doi.org/10.18485/bells.2016.8.1

UDC: 81 '33

\author{
Ranko Bugarski* \\ University of Belgrade \\ Faculty of Philology \\ Serbia
}

\title{
TRADITION IN LINGUISTICS AND TRADITION IN GENERAL
}

\begin{abstract}
After a general definition of the notion of tradition, this paper looks at the ways it has been applied in language study, especially in the history of linguistics and in grammar. Questions concerning the origin, duration, end and possible revitalization of traditions are noted, as are some basic dichotomies: tradition vs modernity, oral vs written, authentic vs invented traditions. It is argued that the meaning of tradition is subject to variation depending on the nature of the disciplines referred to, and that it is easier to talk about tradition in the context of a specific field of study such as linguistics than in general terms, as in the latter case one has to account for a multifaceted and internally contradictory phenomenon.
\end{abstract}

Key words: tradition, history of linguistics, grammar, variability, authenticity

\footnotetext{
* E-mail address: rbugarski@fil.bg.ac.rs
} 


\section{Introduction}

My somewhat unusual title is modelled on that of an article by the Chinese American linguist Yuen Ren Chao, "Models in linguistics and models in general" (Chao 1962), which I read while attending Professor Chao's course on the structure of Chinese at the Linguistic Institute of the Linguistic Society of America, held at the University of Michigan in Ann Arbor in the summer of 1967.

Let me start with a telling quotation. Raymond Williams, in his classic review of the key vocabulary of culture and society, opens the article on "Tradition" with the following sentence: "Tradition in its most general modern sense is a particularly difficult word" (Williams 1983: 318). Rather than summarising his largely historical account, I will offer in this presentation some of my own thoughts on the complexity of the notion, prompted by the topic of our conference. Etymologically, the word comes from Latin tradere 'transmit, hand over for safekeeping'. General definitions given in the major dictionaries (or nowadays perhaps Wiktionaries!) boil down to something like "A belief, custom or behaviour with symbolic meaning or special significance, passed down over a long period of time within a culture, society or group, thus providing it with continuity; principles followed by any branch of art or literature; intergenerational transmission of information and knowledge". With this scope in mind, we may turn to the uses of the term in the study of language.

\section{Tradition in linguistics}

In this area, the most important and least controversial usage is to be found in the history of linguistics, where reference is commonly made to the major traditions of linguistic thought, such as Ancient Indian, Western classical of Greece and Rome, Medieval Arabic and Hebrew, Chinese, etc. This usage is so firmly established that there is no need to dwell on it here, so we will pass on to the next, which is in the province of grammar.

Under this heading the most common phrase is traditional grammar, meaning the approach originating in Graeco-Roman descriptive and normative studies and in subsequent centuries applied especially (and for the most part uncritically) to modern European languages. In the context of linguistic theory, traditional grammar was during the second 
Ranko Bugarski: Tradition in Linguistics and Tradition in General

half of the twentieth century typically opposed to structural and later on transformational-generative grammar, with another dimension contrasting formal and functional grammar, to be followed more recently by cognitive grammar.

Both within and outside these two main areas, history of linguistics and grammar, the notion of tradition is freely used in a number of more specific and variously determined contexts. One of these involves countries (e.g. German, French, British, American linguistic traditions), another particular schools named after cities (such as Kazan, Copenhagen, Moscow or Prague), universities (Yale, Columbia), or aims and approaches (prescriptive vs descriptive traditions). Yet another has to do with periods, either grossly (e.g. classical vs. modern traditions) or in smaller chunks (e.g. $18^{\text {th }}, 19^{\text {th }}, 20^{\text {th }}$ century traditions), but note that the closer one gets to the present the more questionable the use of the word becomes: I don't think that these days anybody would seriously talk of $21^{\text {st }}$ century traditions in anything.

Even path-breaking individual scholars may initiate traditions bearing their names; for example, Humboldtian in ethnolinguistics and philosophy of language, Bloomfieldian or Firthian in descriptive linguistics, Saussurean or Chomskyan in theoretical linguistics, Labovian in sociolinguistics, etc. though note once again the temporal limitation as we approach the present: it is all right to talk of traditions launched even by scholars still living, as the last two mentioned show, but these have to be well past the prime of their lives: one would hesitate to name a tradition after a relatively young person. The same applies to schools of linguistics; it is normal to refer to structuralist, functionalist or generativist traditions, cognitive linguistics has been around for just about the right period of time to join the company, but anything more recent than that would hardly qualify.

\section{Tradition and time}

Examples like these indicate that the notion of tradition by its very nature rests heavily on the passage of time - one could almost say the older, the better! It is, however, impossible to tell how long is enough, i.e. just how old a tradition must be in order to justify such a status; sometimes two generations might do, in other cases many decades or even centuries. 
Likewise, most often it seems futile to try to pinpoint both the beginning and the end of a tradition. The start may in some cases be identified with a single influential figure, as illustrated above, but this is an exception rather than the rule. And the end is even more doubtful, although one may talk loosely about revolutions or paradigm shifts, asociated with works such as Chomsky (1957) and Kuhn (1962), which would seem to suggest the wholesale replacement of an earlier tradition by a new one, as in the case of American sructuralism under the impact of Chomsky's work. Yet a tradition may be revitalized even after a lapse of several centuries, a feat achieved by the "Cartesian linguistics" of Chomsky himself (1966). So what is a dead tradition as opposed to a living one often remains an open question.

\section{Some other dichotomies}

There are several other dichotomies involving the concept of tradition. One of them, presumably uncontroversial, is into oral vs written traditions of folklore and literature respectively. The realm of traditional culture, characteristic of pre-modern societies, with its rituals, folk dances, epic poetry and the rest is mostly oral, though some of it may of course be written down later. As regards the study of language, if we discard the earliest phases of the Eastern traditions in particular, linguistics naturally falls wholly within the realm of writing.

Another frequently invoked division contrasts tradition with modernity, possibly an even more difficult notion which I will conveniently refrain from addressing. As should be clear by now, tradition is in itself quite a mouthful, more than enough for me, and asking in addition what is modern would inevitably entangle one in fashionable queries about what exactly is postmodern, and perhaps also post-postmodern, which I would rather skip. Certainly, the biggest problem here, as well as in the case of some other distinctions, is the methodological one of establishing the dividing line between the members of such pairs.

A rather intriguing controversy has developed recently, however, involving the difference between authentic and invented traditions, the latter concept introduced in the book edited by Hobsbawm and Ranger (1983), where it is claimed that some apparently old traditions may turn out to be actually quite recent or even invented. Examples range 
from Scottish clan tartans, extolled as of ancient origin but in fact a $19^{\text {th }}$ century invention, to an array of myths, symbols and fake historical accounts surrounding the modern phenomena of nations and nationalism, heavily relying on beliefs in their origin in the remote past. In this type of discourse, the notion of tradition is enveloped in the national mythologies of ethnogenesis, focusing on claims about who and what came first, whose language was the oldest, and the like.

To illustrate from the Balkans and a bit further afield, Serbs are not supposed to have arrived in their present territories from anywhere but have always been there, as the oldest nation in Europe if not in the world, and their language is as ancient as Sanskrit, which in fact contains numerous Serbian words; furthermore, the "perfectly phonetic" Serbian Cyrillic script predates, and indeed inspires, Phoenician and Greek writing systems. Such claims are mostly accompanied by fanciful etymologies. For example, if a toponym in any Eurasian language looked remotely like one in Serbia, and especially if it contained the letters $s$ and $r$, this might be offered as proof that Serbs had populated that area in prehistoric times, perhaps as the original settlers. One is reminded here of the dictum attributed to Voltaire, that etymology is a science in which the vowels count for nothing, and the consonants for very little! (Radic 2003 offers an entertaining ridicule of the exotic fantasies of amateur quasi-historians of the so-called "Serb autochthonous school").

We may also sense some invented traditions underlying such popular claims as that the Croats, far from being close relatives of the Serbs, are in fact of Iranian origin and have enjoyed full statehood for a thousand years, while Montenegrins, originating from the Baltic area, have no common history with the Serbs either. Slovenes, or Wends, are likewise distinct from South Slavic peoples, and present-day Macedonians revere Alexander the Great as their most famous forefather. Albanians, deriving in an unbroken line from the ancient Ilyrians, are hence the only original inhabitants of the Balkans, Bulgarians inherit the ancient Thracians, whereas Romanians are the immediate and true descendants of the Roman civilization; and so on.

\section{Attitudes towards traditions}

On the whole, however, attitudes towards traditions are overwhelmingly positive, at least among the general public: traditions are there to be 
respected, cherished and dutifully passed on to new generations, without questioning their authenticity or validity. In this they are comparable to religious beliefs. It is mostly in certain academic contexts that the words tradition and traditional tend to acquire negative overtones. In linguistics one talks neutrally about, for example, traditional phonology or semantics, but traditional grammar is already suspect due to its implicit contrast with structural and generative grammar. When this contrast is made explicit, with these phrases occurring in the same text, describing a grammar as traditional is definitely dismissive: it suggests something oldfashioned, overshadowed by more recent developments, and hence of less value. In the same vein, reference to traditional philology often implies contrasting it with modern linguistics, inevitably at the expense of the former. In the field of education, traditional teaching methods generally enjoy a poor reputation. Interestingly, the further derivatives traditionalist and traditionalism reinforce this negative connotation, strongly suggesting something surpassed or obsolete, opposed to innovation, a point made by Williams (1983: 319-320).

\section{Tradition in different disciplines}

As a professional linguist I can manage to find my way about the ground covered by the first part of my title, tradition in linguistics, despite occasionally possible doubts and queries. Similarly, I assume that experts in other professions have no problems talking about, say, rationalist vs empiricist traditions, the Kantian tradition in philosophy, the Durkheimian in sociology, or the Keynesian in economics. Incidentally, a rough-and-ready indicator is the prefix Neo-: if you can put it in front of something, then that is undoubtedly a tradition (Neo-Humboldtian, Neo-Bloomfieldian, Neo-Firthian, Neo-Chomskyan, Neo-Kantian, Neo-Durkheimian, NeoKeynesian are all well established terms in their respective fields).

It seems to me, however, that the notion of tradition is subject to some considerable variation depending on the nature of the discipline concerned, and moreover that a cline can be established here. At one end would be the "hard" or physical sciences, where the concept may be applied most strictly: a tradition is constituted by adherence to a well-defined system of ideas, research goals and methods, allowing repeated experimentation with a view to confirming or refuting hypotheses, etc.; anything not fitting 
such a paradigm is clearly no part of the tradition. In the "soft" or social sciences, as well as in philosophy, which constitute the middle range of my proposed continuum, tradition tends to be understood more loosely, as a way of thinking about their subject matter. And at the other end I would place literature, where great writers stand out precisely thanks to their individual creative genius which may well keep at bay any potential followers, rather than inviting them.

In other words, whereas in science paradigms, models, research programmes etc. are set up that can be further developed and improved, thus forming a specific tradition, in creative writing any eager disciples would more likely be seen as imitators, in extreme cases risking the charge of plagiarism. As a non-expert I'm treading on slippery ground here, but I suppose literary pundits will know precisely what distinguishes specifically a Dantean or a Shakespearean tradition, as parts of the broader Classical and Elizabethan traditions respectively. Likewise, "Shakespearean tradition" itself may refer to a number of different items: theatre, tragedy, comedy, sonnet structure, stage design, costumes, and so on - and these narrowly focused references seem easier to grasp and interpret than the catch-all expression. And I do not even wish to ask how one might develop, let alone improve, the work of Kafka or Joyce.

My reservations are probably due to a feeling that the very notion of tradition, being based on similarity and continuity, properly implies a collectivity, a number, body or flow of whatever it refers to, and can be individualized to stress outstanding creative achievement, and thereby in effect difference, only secondarily and to a limited extent. But be that as it may, in literature, it would appear, tradition is best understood quite broadly, perhaps along the lines of T.S.Eliot's well-known early essay on the relationship of the individual poet to the tradition he participates in, invoking a "historical sense" of the presence of the past and the living legacy of dead predecessors (Eliot 1921/1950). Indeed, the past in the present is of the very essence of tradition - whereas, to turn the tables just for fun, the present in the past would more likely evoke Schlegel's definition of the historian as a prophet who predicts backwards. 


\section{Tradition in general}

The second part of my title, tradition in general, I find rather more problematic than the first - and this is hardly surprising, given that higherorder abstractions are usually more difficult to handle than their more concrete realizations.

How does one deal with a culturally essential concept that is inescapably time-bound but of indefinite duration; whose beginning and end are frequently hard to identify; which may live, die or be revitalized; which is normally evaluated as positive unless it turns out to be negative, and is therefore carefully safeguarded but may likewise be dismissed as no longer useful or relevant; and which is authentic in all cases when it is not invented?

Frankly, I don't really know, but at least I hope to have suggested why tradition, precisely "in its most general modern sense", is "a particularly difficult word".

Given such a situation, perhaps you will allow me to take refuge in an anecdote. Professor E. Adelaide Hahn, a noted American Indo-Europeanist, known not only for her scholarly achievements but also for her rich and colourful collection of extravagant large hats which she wore as part of her everyday attire, once read a paper before the Linguistic Society of America (of which she was the first lady president, in 1946) entitled "On the accusative of specification in Gothic". Legend has it that after a protracted and complicated discussion she triumphantly declared that there had never been any such thing as the accusative of specification in Gothic; so she apparently delivered a longish lecture on a nonexistent subject. Now why did I remember this particular story, which I heard several decades ago, while preparing my own talk on tradition? Was it purely accidental? I'm not sure. In any case, I certainly do not wish to carry the comparison too far, as there definitely is such a thing as tradition - except that it is too elusive for me to confidently lift the veils covering its many faces and decide which are the prettiest ones. As little Alice might put it, the word somehow seems to fill my head with ideas, only I don't exactly know what they are... 
Ranko Bugarski: Tradition in Linguistics and Tradition in General

\section{References}

Chao,Yuen Ren (1962). Models in linguistics and models in general. Logic, Methodology and the Philosophy of Science (ed. by E.Nagel et al.), Stanford, CA: Stanford University Press, 558-566.

Chomsky, Noam (1957). Syntactic Structures. The Hague: Mouton.

Chomsky, Noam (1966). Cartesian Linguistics: A Chapter in the History of Rationalist Thought. New York: Harper \& Row.

Eliot, Thomas Stearns (1921/1950). Tradition and the individual talent. In The Sacred Wood: Essays on Poetry and Criticism. London: Methuen.

Hobsbawm, Eric and Terence Ranger (eds) (1983). The Invention of Tradition. Cambridge: Cambridge University Press.

Kuhn, Thomas S. (1962). The Structure of Scientific Revolutions. Chicago: University of Chicago Press.

Radić, Radivoj (2003). Srbi pre Adama i posle njega [The Serbs before Adam and after him]. Belgrade: Stubovi kulture.

Williams, Raymond (1983). Tradition. In Keywords: A Vocabulary of Culture and Society. London: Flamingo. 